\title{
Transcriptome and metabolome analyses of two contrasting sesame genotypes reveal the crucial biological pathways involved in rapid adaptive response to salt stress
}

Yujuan Zhang ${ }^{1,2}$, Donghua $\mathrm{Li}^{1}$, Rong Zhou ${ }^{1}$, Xiao Wang ${ }^{1}$, Komivi Dossa ${ }^{1,3}$, Linhai Wang ${ }^{1}$, Yanxin Zhang ${ }^{1}$, Jingyin $\mathrm{Yu}^{1}$, Huihui Gong ${ }^{2}$, Xiurong Zhang ${ }^{1 *}$ and Jun You ${ }^{1 *}$

\begin{abstract}
Background: Soil salinity is one of the major serious factors that affect agricultural productivity of almost all crops worldwide, including the important oilseed crop sesame. In order to improve salinity resistance in sesame, it is crucial to understand the molecular mechanisms underlying the adaptive response to salinity stress.

Results: In the present study, two contrasting sesame genotypes differing in salt tolerance were used to decipher the adaptive responses to salt stress based on morphological, transcriptome and metabolome characterizations. Morphological results indicated that under salt stress, the salt-tolerant (ST) genotype has enhanced capacity to withstand salinity stress, higher seed germination rate and plant survival rate, as well as better growth rate than the salt-sensitive genotype. Transcriptome analysis revealed strongly induced salt-responsive genes in sesame mainly related to amino acid metabolism, carbohydrate metabolism, biosynthesis of secondary metabolites, plant hormone signal transduction, and oxidation-reduction process. Especially, several pathways were preferably enriched with differentially expressed genes in ST genotype, including alanine, aspartate and glutamate metabolism, carotenoid biosynthesis, galactose metabolism, glycolysis/gluconeogenesis, glyoxylate and dicarboxylate metabolism, porphyrin and chlorophyll metabolism. Metabolome profiling under salt stress showed a higher accumulation degree of metabolites involved in stress tolerance in ST, and further highlighted that the amino acid metabolism, and sucrose and raffinose family oligosaccharides metabolism were enhanced in ST.
\end{abstract}

Conclusions: These findings suggest that the candidate genes and metabolites involved in crucial biological pathways may regulate salt tolerance of sesame, and increase our understanding of the molecular mechanisms underlying the adaptation of sesame to salt stress.

Keywords: Salt stress, Sesame, Transcriptome, Metabolome, Metabolic pathway, Amino acid, Raffinose

\section{Background}

Soil salinity as one of the major serious abiotic stresses, occur mainly in coastal and arid/semi-arid regions and affects plant life processes limiting the agricultural productivity and distribution of crops around the world [1, 2]. Currently, more than $20 \%$ of the cultivated land (1000 million ha) is salt affected, and this number is increasing due to global climatic

\footnotetext{
* Correspondence: zhangxr@oilcrops.cn; junyou@caas.cn

${ }^{1}$ Key Laboratory of Biology and Genetic Improvement of Oil Crops of the Ministry of Agriculture and Rural Affairs, Oil Crops Research Institute of the Chinese Academy of Agricultural Sciences, Wuhan 430062, China Full list of author information is available at the end of the article
}

changes and poor management of irrigation and applied fertilizers [2]. Developing salt-tolerant and high yielding plant varieties is the most efficient way to prevent the yield loss in plant production. It is imperative to understand the salinity response and tolerance mechanisms of plants, which helps us develop traditional breeding and biotechnological approaches to improve stress resistance in plants.

High salinity causes hyperosmotic stress, oxidative stress, ionic imbalance, $\mathrm{Na}^{+}$toxicity and even death in plants $[3,4]$. To tolerate the salt stress condition, plants have developed a series of morphological, physiological, biochemical and

C The Author(s). 2019 Open Access This article is distributed under the terms of the Creative Commons Attribution 4.0 International License (http://creativecommons.org/licenses/by/4.0/), which permits unrestricted use, distribution, and 
molecular adjustment mechanisms to keep growth, development and productivity [5]. These acclimation responses include regulation of osmotic adjustment, ion homeostasis, signaling transduction, and induction of antioxidative enzymes activities, etc. [6, 7]. Salt tolerance is a complex trait governed by genetic factors. Many salt-responsive genes, which functions involved in regulation of ion accumulation and exclusion, stress signal transduction, transcription regulation, redox reactions, and accumulation of specific osmoregulation substances, have been identified to play important roles in salt tolerance in many plant species [8]. Transgenic plants achieved by overexpression of some salt tolerance genes exhibits enhanced resistance to salt in different degrees. These genes include AlSAP (an A20/AN1 zinc-finger gene) [9], $B A D H$ (betaine aldehyde dehydrogenase gene) [10], CCD1 (a gene encoding calcium-binding protein with a C-terminal centrin-like domain) [11], PtVP1.1 ( $\mathrm{H}^{+}$-pyrophosphatase gene) [12], $m t l D$ (a gene for mannitol biosynthesis) [13], NHX (a $\mathrm{Na}^{+} / \mathrm{H}^{+}$antiporter gene) [14], P5CS (delta ${ }^{1}$-pyrroline-5-carboxylate synthetase gene) [15], SOS1 (Salt Overly Sensitive pathway gene) [16], OsbZIP23 (basic leucine zipper transcription factor gene) [17]. It's worth noting that durum wheat grain yield on saline soils is increasing by $25 \%$ by introgression of an ancestral $\mathrm{Na}^{+}$transporter gene TmHKT1;5-A in the Nax2 locus from Triticum monococcum [18]. These studies clearly demonstrated that improvements in plant salt tolerance by gene transfer and marker-assisted breeding is highly possible and desirable.

Sesame (Sesamum indicum L.) is one of the oldest oilseed crops worldwide, and considered as an excellent health food for human [19]. Knowledge of the importance of sesame in human nutrition is increasing following reports of the antioxidative activity, antiaging effect, antihypertensive activity, reducing inflammation and atherosclerosis, and other health-related functions of sesame oil and seed components $[19,20]$. In recent years, the demand for high quality sesame seeds in the international market was increased, but the current yield and quality production of sesame cannot meet the increasing demand of the international market [21]. Compared with most of the oilseed crops, sesame is rated relatively salt and drought tolerant crop which should be spread into more coastal and arid/semi-arid areas to increase global sesame production [22]. At present, sesame salt tolerance varieties are urgently needed in these salt-affected zones to overcome salinity effects, especially in Xinjiang and Inner Mongolia regions of China and several African countries. Several studies have mainly focused on the physiological and biochemical responses to salt stress and the identification of some salt-tolerance candidate genes [22-24]. However, there is a lack of scientific studies on the salt tolerance molecular mechanisms and the relationship between the transcriptomic responses and the metabolomic responses to salt stress which are needed to facilitate the developing salt-tolerant sesame varieties. For this study, the transcriptome and metabolome profiles in the seedlings of salt-tolerant and sensitive sesame genotypes were performed in the early phase of salt stress. This study revealed crucial metabolic pathways and metabolites in response to salt stress between the two contrasting genotypes, providing important insights into the mechanisms underlying sesame salt adaptation and tolerance.

\section{Results}

Phenotypic differences between WZM3063 and ZZM4028 in response to salinity stress

Seed germination rates of WZM3063 (salt-tolerant, ST) and ZZM4028 (salt-sensitive, SS) genotypes under control and salt conditions were primarily measured and were found to be more severely affected for SS genotype than ST genotype at $150 \mathrm{mM} \mathrm{NaCl}$ concentration (Fig. 1a and b). Similarly, the capacity to withstand salinity stress was significantly weaker in SS genotype seedlings than ST. ST and SS seedlings exposure to salt stress $(100 \mathrm{mM} \mathrm{NaCl})$ led to leaf chlorosis, leaf tip burning, severe wilting, stunted growth and even to death, but the injury degree was lesser for ST than SS (Fig. 1c). Although differences were observed between ST and SS for shoot length and shoot weight under the control condition, the values of plant survival rate, shoot length and shoot dry weight of SS genotype were reduced much more strongly in SS than ST under salt condition (Fig. 1b). Leaf electrolyte leakage, as indicator of membrane damage, was significantly higher in the SS than in ST under salt stress, suggesting more membrane damage during salt stress in the SS genotype. All these results confirmed that ST genotype withstands salinity stress much better than SS genotype.

\section{Transcriptomic analysis of ST and SS in response to salt stress \\ Overview of the transcriptomic responses of ST and SS to salt stress}

A summary of RNA-Seq data is shown in Additional file 1: Table S1, and revealed that the RNA-Seq datasets are robust quality and reliable results were obtained from the transcriptome assembly. A high correlation between biological replicates was observed $\left(R^{2}>0.92\right)$ for all treatments (Additional file 2: Figure S1), which indicated that the biological replicates were reliable in this study. The principal component analyses (PCA) suggested that the PC1, which represents the difference between the control $(0 \mathrm{~h})$ and treatment groups $(2,6,12,24 \mathrm{~h})$, captured most of the variance in the data (Additional file 3: Figure S2). The samples from the time points could be separated by the PC2, which captured less variance in the data (Additional file 3: Figure S2). In addition, the mRNA expression data also suggested that the expression difference between control and treated groups are dramatically greater than that between different 

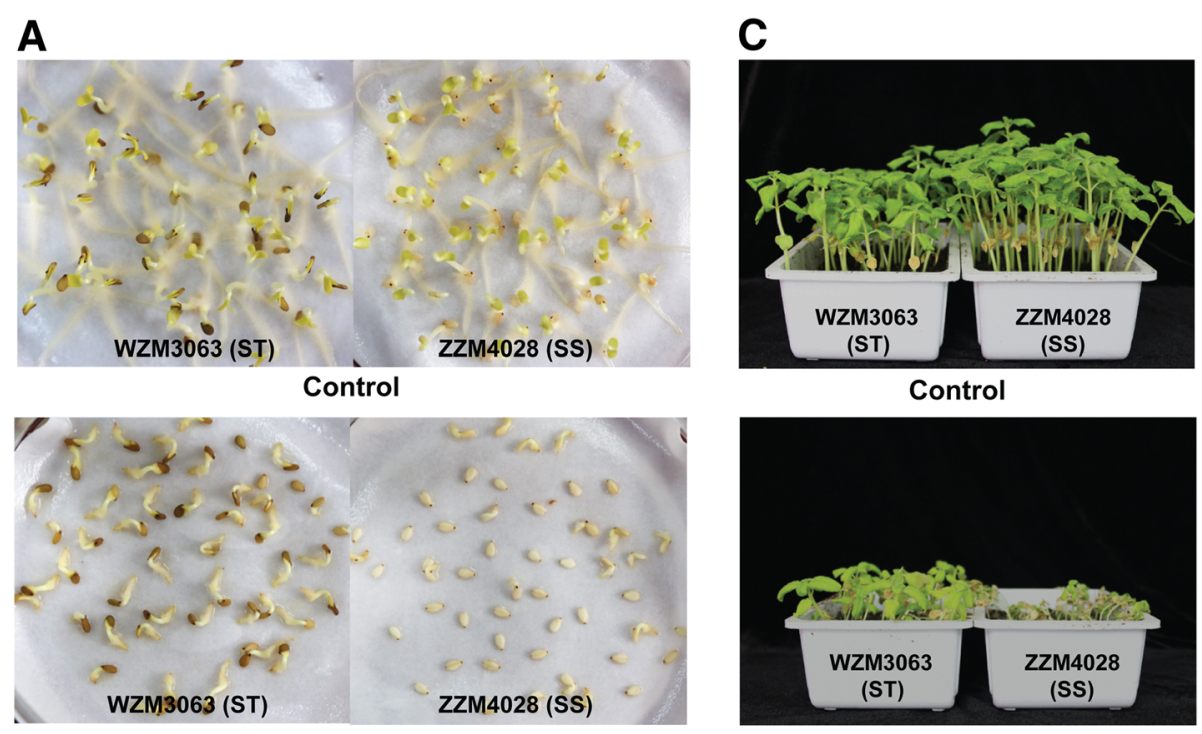

Salt treatment

Salt treatment

\section{B}
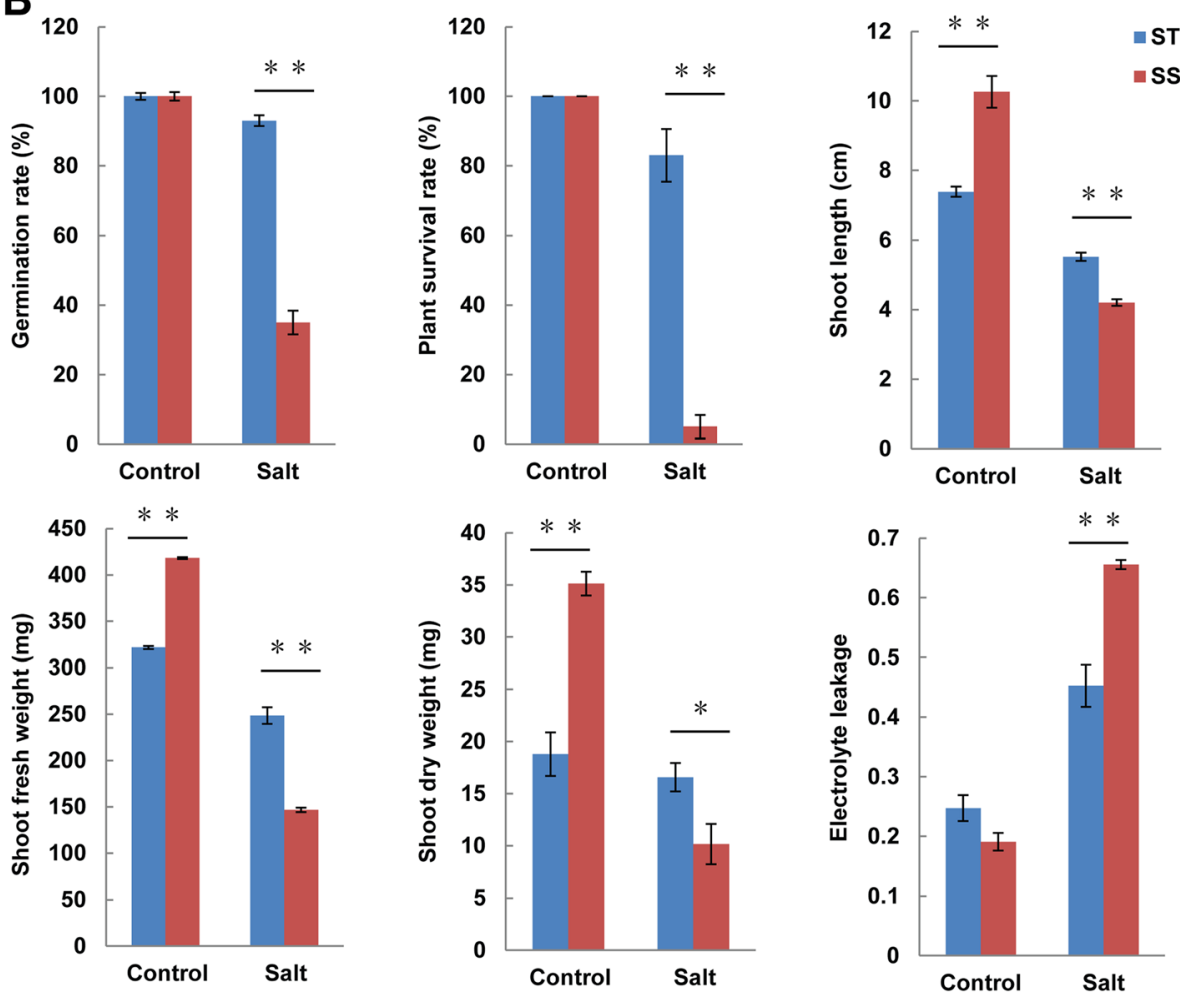

Fig. 1 Morphological changes of salt tolerant (ST) and salt sensitive (SS) in response to salinity stress. a Germination of ST and SS under control and $150 \mathrm{mM} \mathrm{NaCl}$ treatments. b Seed germination rate, plant survival rate, shoot length, shoot fresh weight, shoot dry weight and relative electrolyte leakage of ST and SS under control and salt conditions. c Growth of ST and SS was monitored when 6-days-old seedlings were subjected to $100 \mathrm{mM} \mathrm{NaCl}$ for $21 \mathrm{~d}$. Bars with asterisk $\left(^{*}\right)$ are significantly different $(* P<0.05, * * P<0.01$, two-tailed Student's $t$ tests) between the two genotypes

time points of treatment. The FPKM (fragments per kilobase of transcript per million fragments mapped) value of 10 randomly selected genes in the two genotypes at the four time points under salt treatment (80 comparisons,
$10 \times 2 \times 4)$ was well correlated with its relative expression via $\mathrm{qPCR}\left(\mathrm{r}^{2}=0.86\right.$; Additional file 4: Figure $\left.\mathrm{S} 3\right)$. Figure $2 \mathrm{a}$ summarizes the total number of up- and down-regulated genes of both genotypes under salt stress, revealing that the 
expressions of a large proportion of salt-responsive genes were induced at $12 \mathrm{~h}$ in both genotypes after salt treatment, and the total number of salt-responsive genes in SS was much larger than in ST after exposure to salt stress for $2 \mathrm{~h}$.

\section{Gene set enrichment analysis for the DEGs in response to salt stress}

Compared with control $(0 \mathrm{~h})$, a total of $2227 / 5485$, 5881/ $6928,7969 / 7014$, and $5745 / 6660$ genes were identified to be differentially regulated in ST/SS at 2, 6, 12, and $24 \mathrm{~h}$, respectively (Fig. 2a). Many salt-responsive genes detected at the different sampling times under salt stress were genotype specific and time specific, which may have contributed to the phenotypic differences in salt tolerance between ST and SS (Fig. $2 b$ and c). Gene enrichment analysis of the DEGs based on the KEGG revealed that these genes were mainly involved in several categories, including "amino acid metabolism", "carbohydrate metabolism", "global and overview maps", "lipid metabolism", and "metabolism of terpenoids and polyketides" (Additional file 1: Table S2). Under salt stress, biosynthesis of secondary metabolites and plant hormone signal transduction were enriched significantly in both genotypes at all salt stress time points (Fig. 3). In particular, several pathways were preferably enriched with DEGs in ST genotype at different time points, including galactose metabolism, glycolysis/gluconeogenesis, glyoxylate and dicarboxylate metabolism, alanine, aspartate and glutamate metabolism, porphyrin and chlorophyll metabolism, carotenoid biosynthesis, etc. (Fig. 3). GO enrichment analysis of the DEGs showed that a large number of DEGs were involved in some important GO terms which are known to be associated with salt tolerance in plants, such as oxidation-reduction process, response to hormone, response to abiotic stimulus, oxidoreductase activity, and protein kinase activity (Additional file 5: Figure S4). Moreover, GO analysis also showed apparent genotype- and time-specific results, revealing that some important biological processes, cellular processes and metabolic activities occurred in differently in the 2 genotypes

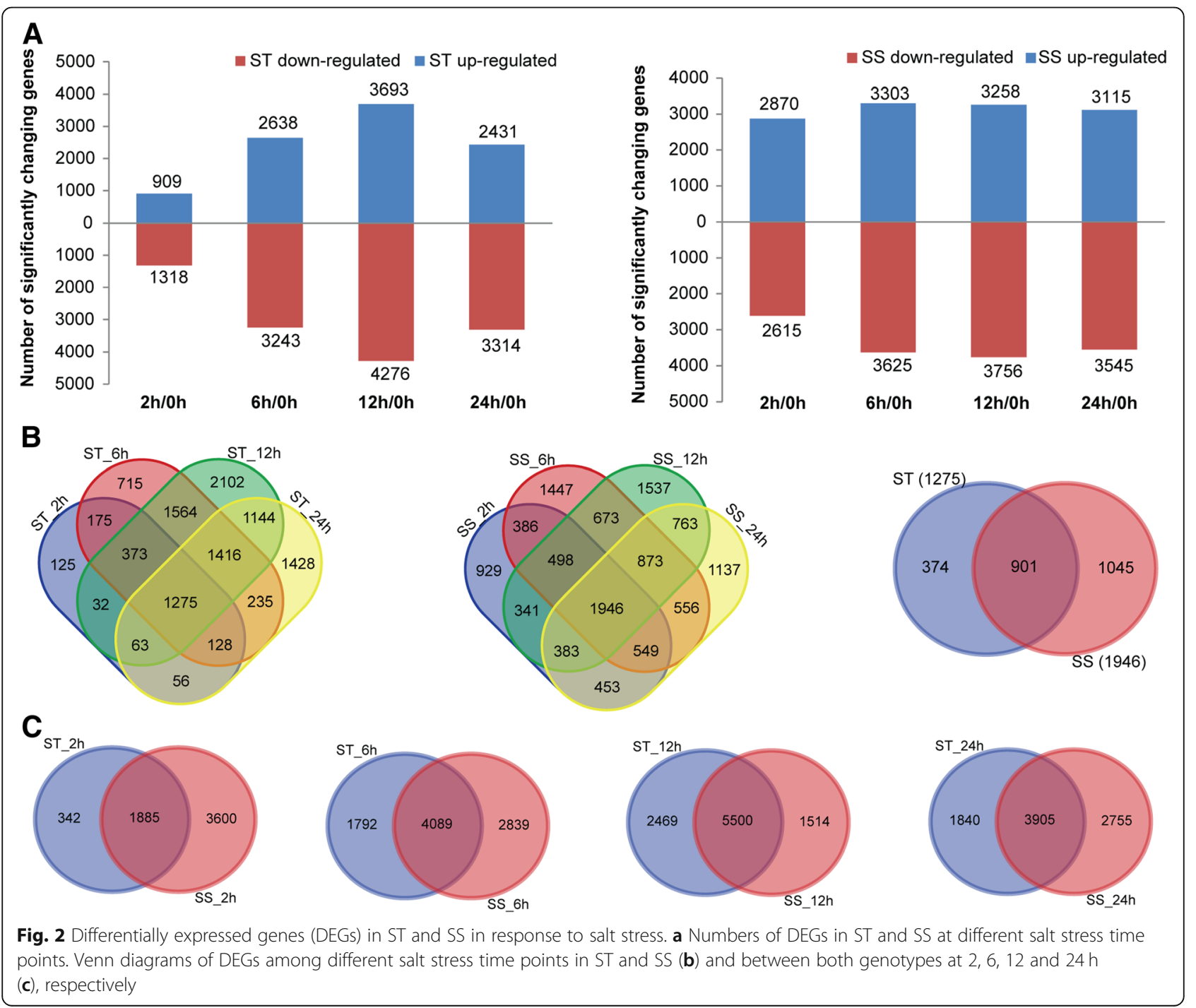




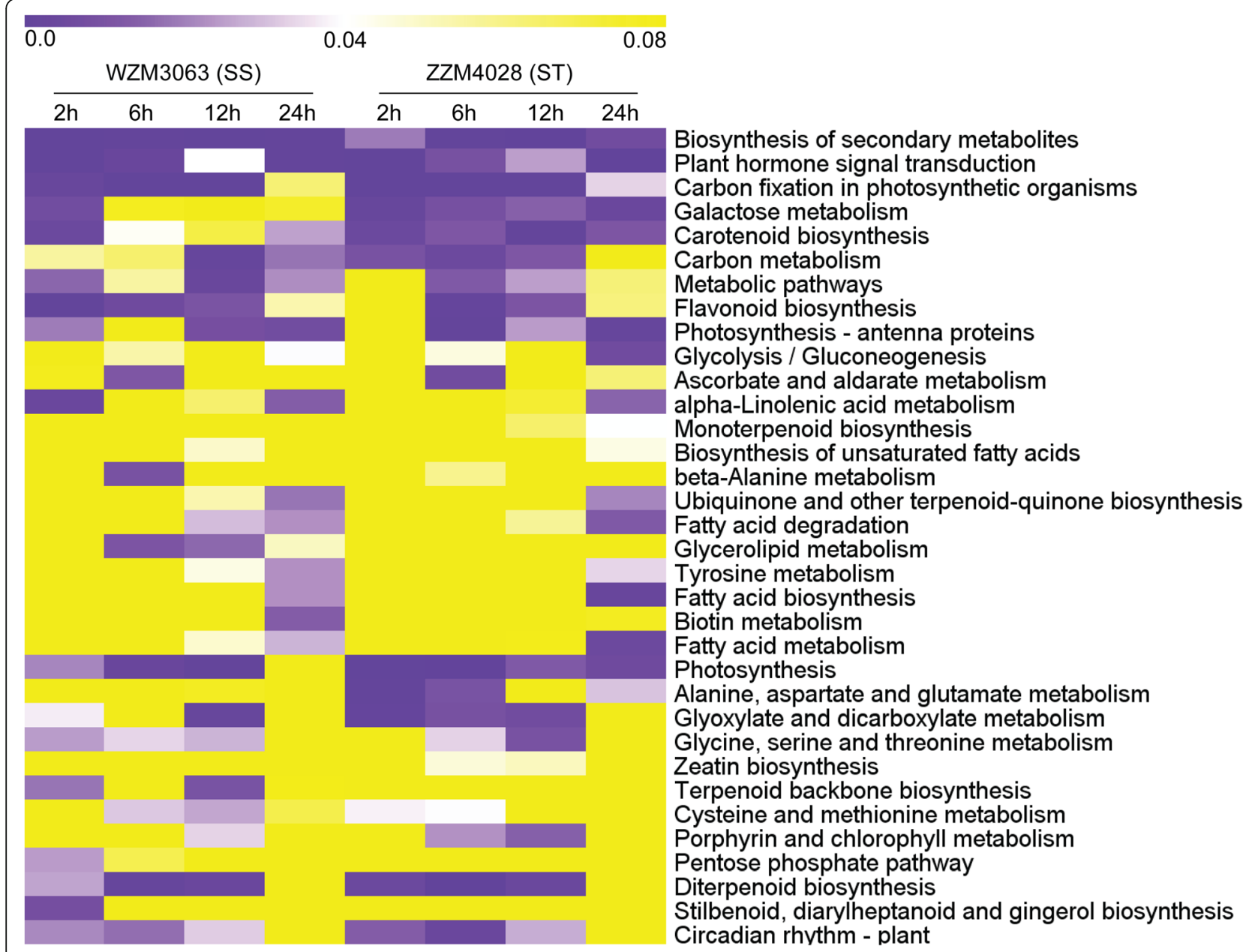

Fig. 3 Heatmap of enriched KEGG pathways of the DEGs in ST and SS at different salt stress time points

under salt stress (Additional file 5: Figure S4). For instance, apoplast, cellular polysaccharide metabolic process, glucan metabolic process, monooxygenase activity, regulation of cellular protein metabolic process, regulation of protein metabolic process, and response to abiotic stimulus were highly or uniquely enriched in ST genotype at different sampling times under salt stress (Additional file 5: Figure S4).

\section{Constitutively active genes of ST and SS genotypes in responses to salt stress}

As shown in Fig. 2b, there were 1275 and 1946 DEGs that were commonly identified in four treatment groups of ST and SS, respectively, while 374 and 1045 DEGs were exclusively found in ST and SS under salt stress, respectively. It is worth noting that 59 genes which were exclusively and highly up-regulated (FPKM $>10$ during at least one time point) in ST at all time points after salt treatment were identified as candidate genes for improved salt tolerance in ST (Additional file 1: Table S3). Of these, several genes of regulatory function were notable, such as ABC transporter (LOC105170264), $\beta$ - glucosidase (LOC105173929), cytochrome P450 (LOC105161642), dehydration-responsive elementbinding protein (LOC105157670), UDP-glycosyltransferase (LOC105171082) (Additional file 1: Table S3). Although different sets and numbers of genes were expressed by the two genotypes, a total of 901 genes (206 up- and 695 down-regulated) were constitutively active in both genotypes and represent the core genes associated with response to salt stress despite tolerance levels in sesame, including a lot of heat-shock proteins, heat-shock transcription factors, late embryogenesis abundant proteins (LEAs), probable protein phosphatase 2C (PP2Cs) (Fig. 2b, Additional file 1: Table S4). Especially, among these core genes, a total of 101 transcription factors were identified which grouped into 31 families, including AP2-EREBP, bHLH, bZIP, HB, MYB, NAC, and their diverse expression patterns indicate their important regulatory roles in salt stress responses (Additional file 1: Table S4, Additional file 6: Figure S5). Alterations in their expression could significantly affect translation of 
other proteins under salt stress. Based on the GO enrichment analysis, the 901 core genes were found to participate in some important biological processes, including response to auxin, response to hormone, cellular glucan metabolic process, response to abiotic stimulus, polysaccharide metabolic process, protein phosphorylation, and glutamine biosynthetic process (Additional file 1: Table S5). Moreover, many genes were enriched in molecular functions related to kinase activity, protein kinase activity, hydrolase activity, hydrolyzing O-glycosyl compounds and hydrolase activity, acting on glycosyl bonds (Additional file 1: Table S5).

\section{Metabolic analysis of ST and SS in response to salt stress}

In total, 282 metabolites were detected in sesame by liquid Chromatograph Mass Spectrometer (LC-MS) and Gas Chromatography Mass Spectrometer (GC-MS), including a lot of primary and secondary metabolites, such as amino acids, lipids, organic acids, sugars, alkaloids, amines, flavonoids, terpenoids etc. Compared with control $(0 \mathrm{~h}), 145$ measured metabolites were identified to be significantly changed in ST or SS genotypes at $12 \mathrm{~h}$ or $24 \mathrm{~h}$ after salt stress. In order to find out if the metabolomics profiles of treated and control plants differ from each other PCA was performed. The PCA shows a clear separation between the time points by $\mathrm{PC} 1$ and the separation of genotypes can be observed by PC2 (Fig. 4a). In addition, the biological replicates were projected closely in the space, which indicated a good correlation between replicates. The numbers of metabolites that were significantly increased and decreased in one or both genotypes in response to salt stress exposure are presented in Fig. 4b and c, revealing that most of the measured metabolites are increased after salt treatment. Through metabolic pathway mapping, the changed metabolites in response to salt stress were mainly involved in amino acid metabolism, raffinose family oligosaccharides metabolism, citrate cycle (TCA cycle), glycolysis/gluconeogenesis and urea cycle, suggesting that these metabolic pathways may play important roles in rapid adaptive response to salt stress in sesame (Additional file 7: Figure S6).

In total, 31 increased and only one decreased metabolites were shared by both genotypes and represent the core metabolites in sesame response to salt stress (Fig. 4b and c, Additional file 1: Table S6). Among them, the accumulation levels of 13 free amino acids, 8 sugars (containing sugar derivatives) and abscisic acid (ABA) were significantly increased in both genotypes under salt stress, indicating their important roles in osmotic regulation contributing to

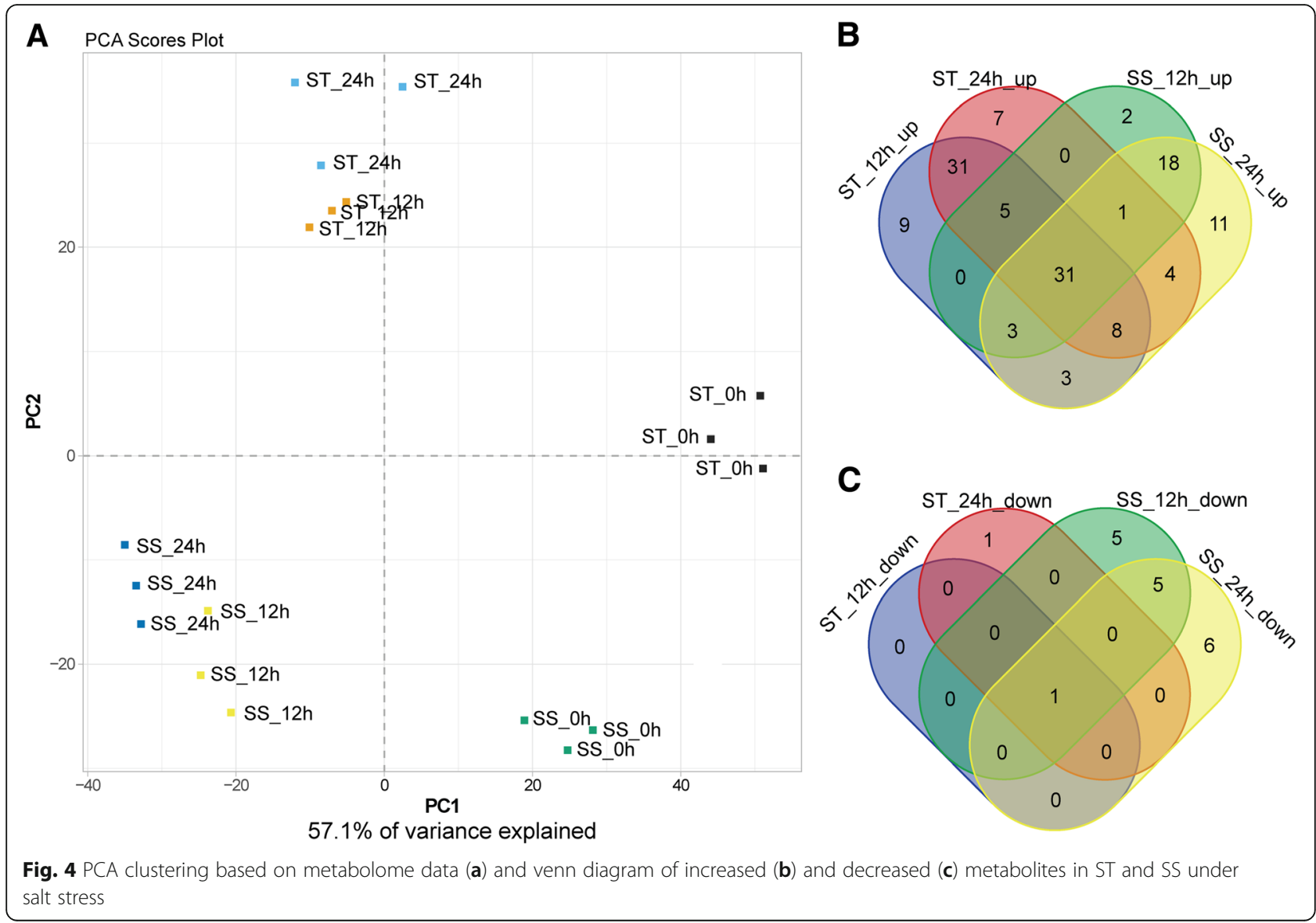


salinity tolerance of sesame (Additional file 1: Table S6). As shown in Fig. 4b and c, a lot of changed metabolites at 12 $\mathrm{h}$ and $24 \mathrm{~h}$ under salt stress were also genotype specific. Particularly, 47 measured metabolites showed exclusively significant increase at $12 \mathrm{~h}$ or $24 \mathrm{~h}$ in ST genotype under salt treatment, including 7 free amino acids, 6 dipeptides, 10 sugars and sugar derivatives, 11 organic acids, caffeic acid, spermidine, etc. (Additional file 1: Table S7). Notably, the aspartate content increased by 13.0-fold and 12.5-fold in ST at $12 \mathrm{~h}$ and $24 \mathrm{~h}$ under salt stress, respectively, while the glutamate content increased by 17.9-fold and 26.4-fold in ST at $12 \mathrm{~h}$ and $24 \mathrm{~h}$ under salt stress, respectively (Additional file 1: Table S7).

\section{Association of transcriptomic and metabolomic changes involved in crucial biological pathways}

To obtain more informational perspective on the physiological changes in response to salt stress in sesame, we focused on the connection between gene expression and salt-responsive metabolites changes. In general, several genes encoding key enzymes were involved in either biosynthesis or degradation process of crucial metabolites, suggesting that these genes could be valuable targets for improved salt tolerance in sesame.

\section{Amino acid metabolism in sesame during salinity stress}

It is noteworthy that pathways involved in amino acid metabolism were enriched significantly in both transcriptomic and metabolomic data. Figure $5 \mathrm{~A}$ shows the amino acid metabolic pathways and the general pattern of the relative changes of related metabolites in ST and SS genotypes under salt condition. The content of most free amino acids considered as osmotic regulatory substances, was significantly increased in one or both genotypes, implying that the accumulation of free amino acids is crucial in sesame response to salt stress (Fig. 5a). Obviously, the induction rate of accumulation of many free amino acids (including alanine, asparagine, aspartate, glutamate, glutamine, glycine, isoleucine, leucine, lysine, methionine, ornithine, phenylalanine, proline, serine, threonine, tyrosine, and valine) was more higher in ST than in SS, which may be a positive feature for withstanding salinity stress in ST genotype (Fig. 5a). The expression patterns of the genes involved in the amino acid metabolic pathways were presented in detail in Fig. 5b. In the pathways leading to the strong salt-induced accumulation of arginine, glutamine, glycine, methionine, ornithine, phenylalanine, and tyrosine, most of genes involved in the biosynthesis of these amino acids were up-regulated in both genotypes under salt stress, although there was a trend of down-regulation among some enzymes of these pathways (Fig. 5b). In particular, several genes involved in the biosynthesis of aspartate, threonine, methionine, tyrosine and phenylalanine, showed higher changes in ST than in SS at $12 \mathrm{~h}$ or $24 \mathrm{~h}$

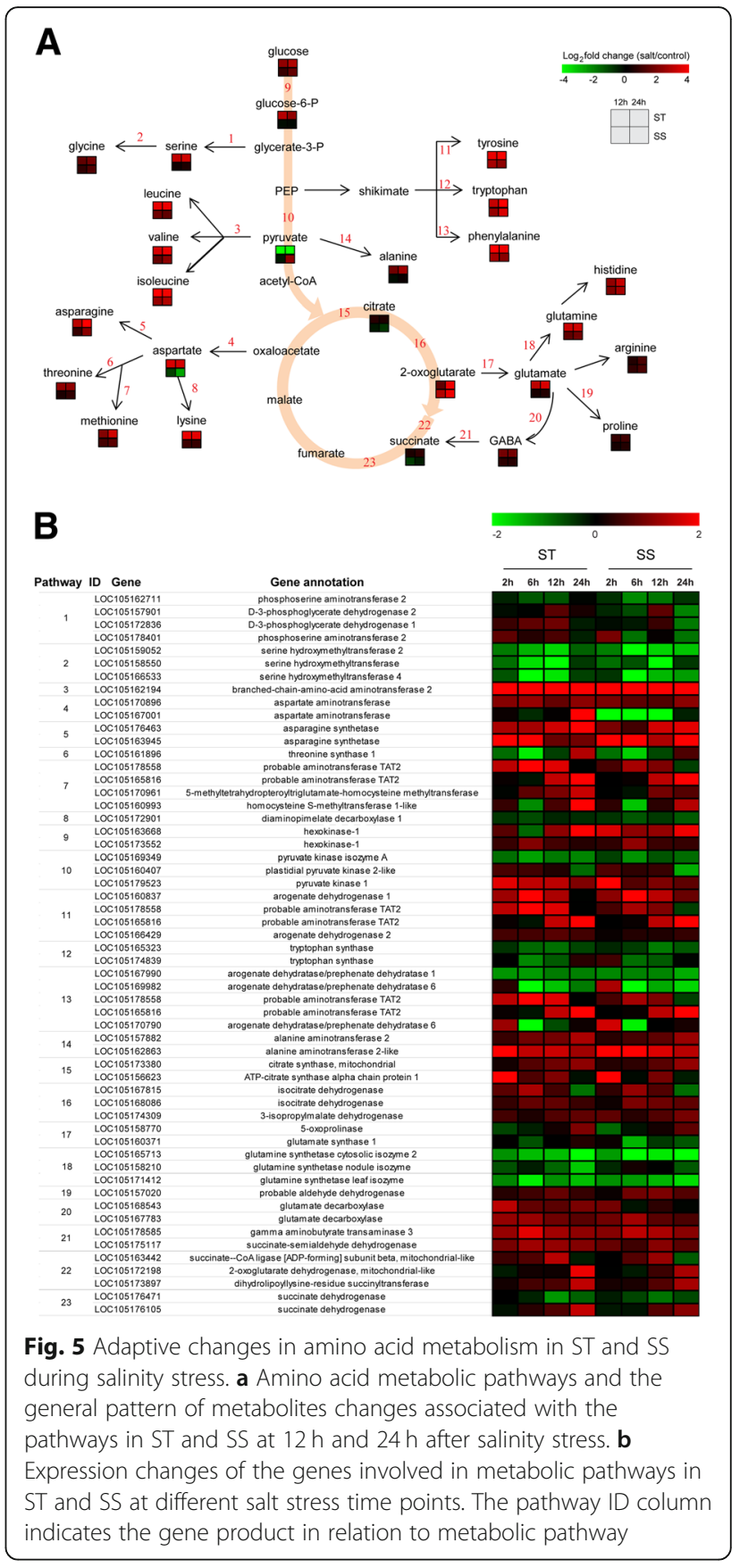

after exposure to salt, such as aspartate aminotransferase (LOC105167001), threonine synthase 1 (LOC105161896), 5-methyltetrahydropteroyltriglutamate-homocysteine methyltransferase (LOC105170961), homocysteine Smethyltransferase 1-like (LOC105160993), probable aminotransferase TAT2 (LOC105178558). LOC105162194 encoding a branched-chain-amino-acid aminotransferase 2 which is involved in the different pathways leading to the synthesis of isoleucine, leucine and valine, was significantly and continuously up-regulated in both genotypes after salt stress (Fig. 5b). This adjustment of genes may be 
important to maintain the biosynthesis of some amino acids under stress. Some genes encoding enzymes of serine hydroxymethyltransferase, tryptophan synthase, and glutamine synthetase tended to be down-regulated in both genotypes at almost all time points after salt treatment, so the greatly increased accumulation of serine, tryptophan, and glutamine could be mainly due to greatly reduced degradation (Fig. 5b). Moreover, 4-Aminobutanoic acid (GABA) as an important derivative from glutamate was observed strongly salt-induced in ST genotype, while the expressions of genes for glutamate decarboxylase involved in GABA biosynthesis pathway were up-regulated remarkably in ST under salt stress, especially at $24 \mathrm{~h}$. In general, the integration of both omics data revealed that amino acid metabolism is strongly enhanced for contributing to salt tolerance in sesame, especially in ST genotype.

\section{Alterations in sucrose and raffinose family oligosaccharides metabolism after exposure to salt} The raffinose family oligosaccharides (RFOs), such as raffinose and stachyose, play an important role in protection against abiotic stress [25]. Figure 6a showed the schematic presentation of sucrose and RFOs biosynthetic pathways in sesame. Interestingly, most of metabolites accumulation involved in sucrose and RFOs metabolism including galactinol, myo-inositol, raffinose, stachyose, sucrose, melibiose, fructose, glucose, were significantly increased in the two genotypes under salt stress, but their fold changes were consistently higher in ST than in SS (Fig. 6a). The expression patterns of most genes involved in the same pathway were similar in the two contrasting genotypes in response to salt stress (Fig. 6b). Three genes encoding galactinol synthase 2 (EC 2.4.1.123) that plays a key regulatory role in the synthesis of galactinol were up-regulated in both genotypes under salt stress, but the expression of gene (LOC105168975) was increased more higher in ST compared with SS under salt treatment (Fig. 6b). Galactinol-sucrose galactosyltransferase (EC 2.4.1.82) and stachyose synthase (EC 2.4.1.67) catalyze the key steps for the synthesis of raffinose and stachyose. The accumulation of raffinose and stachyose which were strong salt-induced both in ST and SS genotypes could be primarily attributed to strong salt-induced expression of a galactinol-sucrose galactosyltransferase gene (LOC105162538) and a stachyose synthase gene (LOC105178881) by salt stress. In addition, most of genes involved in the pathways leading to the accumulation of sucrose, melibiose, fructose and glucose were also up-regulated in both genotypes in response to salt stress. Therefore, these results suggested that the salt tolerance ST genotype could be related to the stronger ability to regulate carbohydrates accumulation in sucrose and RFOs metabolism.

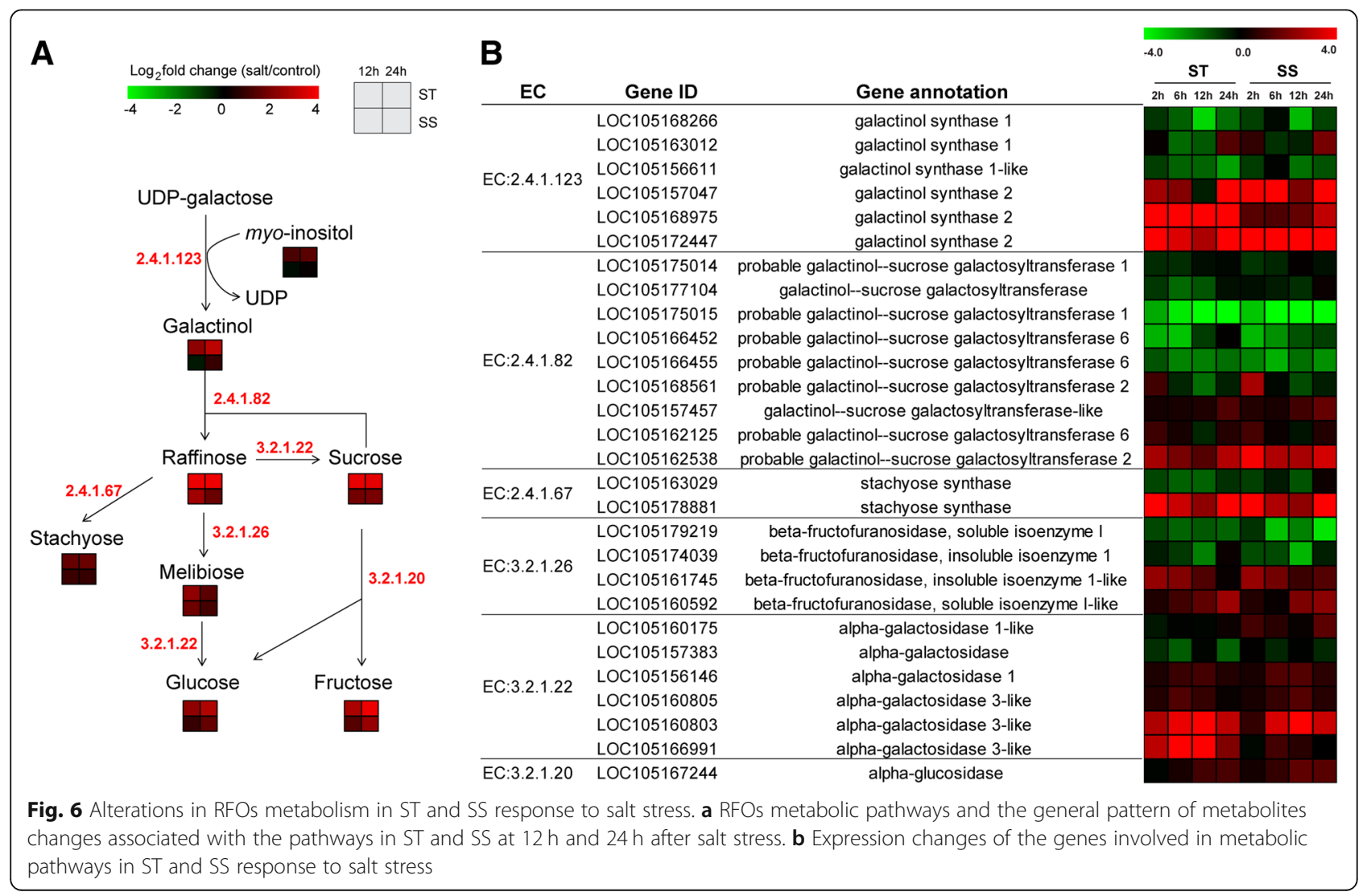




\section{Discussion}

Salt stress as one of the major environmental factors that influence the worldwide distribution of plants, limits growth and productivity of plants, and threatens food security. It is necessary to identify major salt response and tolerance mechanisms in plant to improve crop salt stress resistance. Here, we tracked the transcriptomic and metabolomic changes in sesame seedlings of two contrasting genotypes under salt stress over a period of $24 \mathrm{~h}$, which could provide us with a unique opportunity to gain insights into the candidate genes and metabolites involved in metabolic pathways underlying salt tolerance in sesame.

\section{Osmotic adjustment under salt stress}

High salt level has osmotic effect on plant cells [5, 7]. When plants are subjected to salt stress, the osmotic stress immediately reduces cell expansion in root tips and young leaves, and drastically reduces stomatal conductance [7, 26]. Many plants can accumulate compatible solutes to maintain a stable osmotic pressure and protect membranes and proteins from degradation by mediating osmotic adjustment [27, 28]. Consistent with previous findings, our research showed that strong salt-induced accumulation was observed for most of amino acids, sugars (maltose, melibiose, raffinose, stachyose, sucrose, tagatose and trehalose), and sugar alcohols (erythritol, inositol, xylitol) in sesame, especially in ST genotype (Figs. 5a and 6a, Additional file 1: Tables S6 and S7), while many of them have been recognized as osmolytes in the cytoplasm under salt stress in plants [29,30]. Recent studies of genes controlling the synthesis or metabolism of several osmolytes have suggested their important roles in salt tolerance, such as mtlD [13], P5CS [15], OTS [31]. In addition to function as compatible solutes, amino acids could serve as the precursors of secondary metabolites protecting plants from stresses [32, 33]. Previous reports showed that some metabolites involved in plant defense responses were synthesized from amino acid metabolic pathways, which demonstrated that amino acid metabolism play key functions in response to stress in plants [34,35]. Specifically, the glutamate content in ST increased over 17.9-fold under salt stress, implying that glutamate may serve as a key player in salt tolerance in sesame. Glutamate is the precursor of proline and GABA, and one of the tripeptides in glutathione, as well as serves as substrate for converting to $\alpha$-ketoglutaric acid which is an important intermediate of carbon and energy metabolism [36]. Here, we observed the induction of several genes involved in amino acid metabolism, sucrose and RFOs metabolism, as well as other sugars biosynthesis, which was consistent with our observation of salt-induced accumulation for special metabolites (Figs. 5b and 6b). In short, our transcriptomic and metabolomic analysis strongly revealed that salt-induced accumulation of these important metabolites through synthesis or metabolism pathways may contribute directly to improving salt tolerance of sesame.

\section{Reactive oxygen species (ROS) homeostasis during salinity stress}

In plant, salt stress causes the accumulation of ROS (such as ${ }^{1} \mathrm{O}_{2}, \mathrm{H}_{2} \mathrm{O}_{2}, \mathrm{O}_{2}$-- and $\mathrm{HO}$,) that result in oxidative damage and programmed cell death [37]. On the other hand, ROS might act as signal molecules to regulate stress responses rapidly [38]. Previous studies reported that the $\mathrm{Na}+$-induced stabilization of SOS1 mRNA is mediated by reactive oxygen species [39]. The connection between SOS pathway and ROS signaling was further demonstrated through the interaction of SOS2 with both NDPK2 (nucleoside diphosphate kinase 2) and catalases [40]. To maintain the ROS homeostasis under stressful conditions, plants have evolved antioxidative defense mechanisms, including ROS scavenging system [41]. During stress, ROS scavenging enzymes such as ascorbate peroxidase, catalase, peroxidase, glutathione S-transferase, and superoxide dismutase, are essential for ROS detoxification [42]. Previous studies have shown that ROS scavenging mechanisms play important roles in protecting plants against salt stress [42-44]. In this study, transcriptomic data revealed that a large number of DEGs both in ST and SS were related to oxidation-reduction process and oxidoreductase activity, suggesting that oxidative stress might be activated at the preliminary stage in response to salt stress. Furthermore, certain salt responsive genes encoding enzymes which involved in ROS scavenging system, including peroxidase and glutathione S-transferase, were strongly up-regulated both in ST and SS under salt stress, implying that regardless of the salt tolerance level, ROS scavenging system is an important protection or tolerance mechanism in sesame adaptive response to salt stress.

\section{Ionic adjustment in response to salt stress}

In plant responses to salt stress, ion homeostasis such as $\mathrm{Na}^{+}$and $\mathrm{K}^{+}$is important for maintaining cytosolic enzymes activities, membrane potential and an appropriate osmotic pressure of cells [45]. The detrimental effect of salt stress on most plant growth and development was mainly caused by $\mathrm{Na}^{+}$toxicity, and so most intensive studies was concentrated on $\mathrm{Na}^{+}$stress signaling, $\mathrm{Na}^{+}$exclusion, and $\mathrm{Na}^{+} / \mathrm{K}^{+}$transport $[46,47]$. The Salt-Overly-Sensitive (SOS) pathway is well known for salt stress signaling and $\mathrm{Na}^{+}$tolerance so far in plant species, such as Arabidopsis [46], poplar [48], tomato [49] and wheat [50]. In this pathway, SOS3 (EF-hand calcium-binding protein) could sense the cytosolic calcium signal elicited by salt stress, and interact with and activate a serine/threonine protein kinase SOS2 [51]. The activated SOS2 phosphorylates and activates SOS1 (a $\mathrm{Na}^{+} / \mathrm{H}^{+}$antiporter at the plasma membrane), which may function to extrude $\mathrm{Na}^{+}$from the xylem parenchyma cells into the apoplastic space of mesophyll cells $[47,51]$. In both sesame genotypes, we observed the salt-induction of many genes for the SOS pathway components, including 
calmodulin-binding proteins, CBL-interacting protein kinases (CIPKs), together with the $\mathrm{Na}^{+} / \mathrm{H}^{+}$exchangers (NHXs), suggesting that SOS pathway is pivotal regulator of $\mathrm{Na}^{+}$homeostasis in salt tolerance of sesame materials with different salinity tolerance levels. Vacuolar and plasma membrane NHXs are key regulation factors that reduce accumulation of $\mathrm{Na}^{+}$by transporting them across the tonoplast into vacuoles $[46,52]$. Transcriptomic data revealed that a gene for sodium/hydrogen exchanger 4, was found to be induced strongly in $\mathrm{ST}$ at $2 \mathrm{~h}$ after salt stress, suggests that $\mathrm{Na}^{+}$stress signaling could be strongly and rapidly activated in ST when subjected to salt stress. On the other hand, recent studies showed that maintaining a high cytosolic $\mathrm{K}^{+}$to $\mathrm{Na}^{+}$ratio is important for plant cell metabolism and extra $\mathrm{K}^{+}$could mitigate $\mathrm{Na}^{+}$toxicity $[45,53,54]$. Therefore, $\mathrm{K}^{+}$homeostasis is also important for plant withstanding under salinity stress. In this study, salt stress increases the transcript level of some genes encoding $\mathrm{K}^{+}$transporter and $\mathrm{K}^{+}$channel in sesame. Particularly, several genes for $\mathrm{K}^{+}$channel AKT2/3 and KAT3 and $\mathrm{K}^{+}$transporter 6 were induced strongly only in ST genotype under salt stress, indicating that ST genotype may have a stronger ability of $\mathrm{K}^{+}$transport to maintain ion homeostasis in response to salt stress.

\section{ABA signal transduction}

In this study, functional analysis of DEGs by KEGG and GO enrichment analysis revealed that a large number of genes were involved in plant hormone signal transduction and response to hormone under salt stress, highlighting the pivotal roles plant hormones in regulating sesame responses to salinity stress. In particular, the ABA signaling pathway is well known to be associated with responses to salt stress in plants and ABA content increase could help plants to adapt and survive under salt condition by reducing the accumulation of $\mathrm{Na}^{+}$and improving osmotic adjustment $[47,55]$. Our metabolomic data showed that the content of ABA was increased dramatically in the two contrasting genotypes after salt treatment in different ways (Additional file 1: Table S6). The genes for 9-cis-epoxycarotenoid dioxygenases, rate-limiting enzymes in the initial steps of ABA biosynthetic pathway, were also significantly up-regulated in both genotypes during salt treatment (Additional file 1: Table S4). In addition, ABA could be released from the ABA glucosyl ester form stored in vacuoles and apoplasts by $\beta$-glucosidase [56]. Here, a gene for $\beta$-glucosidase was found to be exclusively and highly up-regulated in ST genotype under salt stress (Additional file 1: Table S3). Therefore, rapid accumulation of ABA induced by salt stress in SS could be mainly due to enhancing of ABA biosynthesis, but in ST could be partially due to strongly increased $\mathrm{ABA}$ biosynthesis and partially released from the ABA glucosyl ester. Recently, the core ABA signaling pathway has been elucidated following with the identification of ABA receptors (PYR/PYL/RCAR protein family), PP2Cs, and subfamily 2 of the SNF1-related kinases
(SnRK2s) [57, 58]. SNF1-related kinases could activate ABA-responsive element binding transcription factors (AREB/ABFs) which containing a bZIP-type DNA-binding domain and positively regulating the expression of $A B A-$ or stress-regulated genes, such as $L E A s$ [59, 60]. Moreover, it has been confirmed that a bZIP protein could interact with both transcription factor VP1 and ABA-responsive elements and mediate ABA signals [61]. Transgenic plants overexpressing bZip or $L E A$ alone showed significantly improved tolerance to salt and drought stresses, while co-transfer of bZip and LEA exhibited an apparent additive effect on stress-tolerance [17, 62]. In this study, we found that a group of PYLs, PP2Cs, SnRK2s, AREB/ABFs, VP1, and LEA genes in sesame were strongly and rapidly induced or inhibited under salt stress, suggesting that these genes may play crucial roles in ABA signal transduction and protecting sesame from damage caused by salt stress (Additional file 1: Table S4). Further studies should focus on the functional analysis of these candidate genes, which is necessary to identify the protein-protein interactions in adaptive response to salt stress and study the genetic basis of natural variation in salinity tolerance of sesame.

\section{Other salt stress response related metabolites}

It is also worth noting that some important metabolites such as GABA, spermidine and caffeic acid, were highly increased in ST when treated with salt stress (Fig. 5a, Additional file 1: Table S7). Recent studies show that GABA, spermidine and caffeic acid play important roles in improving plant tolerance to salt and other stresses [63-65]. GABA is a derivative from glutamate and as a signal molecule, participates in regulating the expression of genes involved in reactive oxygen species (ROS) scavenging in plants under salt stress $[63,66]$. The genes encoding glutamate decarboxylase that contribute to GABA biosynthesis were also observed strongly salt-induced in ST genotype, suggesting their important regulatory roles in sesame response to salt stress (Fig. 5b). Spermidine is one of the major polyamines that participate in the regulation of cellular proliferation and differentiation [64]. High elevation of spermidine level is correlated with salt tolerance in plants $[67,68]$. Exogenous application of spermidine could improve salt tolerance in plants by maintaining $\mathrm{K}^{+} / \mathrm{Na}^{+}$homeostasis, enhancing activity of antioxidant enzymes, increasing the osmolytes level and preventing cellular membrane damage $[68,69]$. In this study, most of genes involved in spermidine biosynthesis and degradation pathways were inhibited by salt stress, implying that the increased accumulation of spermidine could be mainly attributed to greatly reduced degradation. For caffeic acid, recent studies show that 4-coumarate-CoA ligase can protect plant against adversity stress through enhancing activity of antioxidant enzymes and regulating soluble sugar and proline contents $[70,71]$. We also observed that the 
caffeoylshikimate esterase and 4-coumarate:CoA ligase genes which participate in caffeic acid biosynthesis and degradation, were up-regulated and down-regulated in ST under salt stress, respectively, probably resulting in the accumulation of caffeic acid in sesame as an adaptive response.

\section{Conclusions}

In summary, using our transcriptomic and metabolomic dataset, we successfully identified a lot of candidate genes and metabolites involved in crucial biological pathways underlying salt tolerance in sesame. Our data suggested that the main salt tolerant characters in sesame could be attributed to not only a single gene or metabolite, but a complex regulation and signaling mechanisms, and further studies should focus on how do these candidate genes or metabolites participate in the salt tolerance of sesame.

\section{Methods}

\section{Plant materials and experimental design}

Two sesame accessions of salt-tolerant WZM3063 (ST) and salt-sensitive ZZM4028 (SS) were obtained by salt tolerance evaluation for 490 sesame core collections preserved at the China National Genebank, Oil Crops Research Institute, Chinese Academy of Agricultural Sciences [22]. The sesame seeds were sterilized with $3 \%$ sodium hypochlorite for 10 min and washed four times using sterile water. The seeds were germinated on two filter papers with sterile water in an illuminated incubator using a $16 / 8 \mathrm{~h} \mathrm{light/dark}$ cycle at $28^{\circ}$ C. Three days later, the uniform seedlings were placed in a box containing half-strength Hoagland solution. 14-day-old seedlings were treated with $150 \mathrm{mM} \mathrm{NaCl}$ for different time points. The shoots of treated seedlings were harvested at 0 (control), 2, 6, 12 and 24 $\mathrm{h}$ for transcriptome sequencing and the same samples of 0 (control), 12 and $24 \mathrm{~h}$ were prepared for metabolite profiling (three biological replicates per treatment). All samples were immediately placed in liquid nitrogen and stored at $-80^{\circ} \mathrm{C}$ until use.

\section{Phenotyping characterization}

To assess the salt tolerance of the two genotypes at the germination stage, the sterilized seeds of the two cultivars were germinated on two filter papers with purified water (control) and $150 \mathrm{mM} \mathrm{NaCl}$ (with 3 replicates) in a dark illuminated incubator at $28{ }^{\circ} \mathrm{C}$, respectively. Subsequently, the germination rate was recorded at 6 days (d). For salt tolerance assessment of the two cultivars at the seedling stage, the seeds of ST and SS were sown in differently boxes containing nutrient soil for $6 \mathrm{~d}$. Then, the uniform seedlings were subjected to no-stress control and salinity $(100 \mathrm{mM} \mathrm{NaCl})$ conditions with three replications for $21 \mathrm{~d}$. Plant survival rate, shoot length, shoot fresh weight, and shoot dry weight of the seedlings under control and salinity conditions were measured. Electrolyte leakage was determined using the method as previous described [72].

\section{Total RNA isolation and transcriptome analysis}

Total RNA of 30 samples was extracted using an EASYspin Plus kit (Aidlab, Beijing, China). RNA-Seq libraries were prepared and sequenced on an Illumina Hiseq $\mathrm{X}$ ten platform (Novogene Company, Beijing, China) according to the methods described earlier [73]. After filtering adapters and low-quality sequences, the clean reads were mapped to the sesame genome v.1.0 (https://www.ncbi.nlm.nih.gov/genome/?term=sesamum) using HISAT [74]. Novel transcript prediction and gene expression analysis were carried out as described by Dossa et al [75]. Gene expression level for each sample expressed was according to the FPKM. PCA for evaluating relationships among samples was performed using the software $\mathrm{R}$ version 3.1.1. A significant false discovery rate-adjusted $P$ value (FDR) $<0.05$ based on three biological replicates was used as the empirical parameter to identify the differentially expressed genes (DEGs) [76]. Gene Ontology (GO) and Kyoto Encyclopedia of Genes and Genomes (KEGG) enrichment analysis for the DEGs were carried out by GOseq [77] and KOBAS (2.0) software, respectively. Hierarchical clustering analysis of the DEGs was performed using the $\mathrm{MeV} 4.9$ software [78].

\section{LC-MS and GC-MS metabolite measurements and data analysis}

Metabolites extraction was performed according to metaSys X standard procedures, a modified protocol from Giavalisco et al. [79]. The samples were measured with a Waters ACQUITY Reversed Phase Ultra Performance Liquid Chromatography (LC) coupled to a Thermo-Fisher Exactive mass spectrometer (MS) which consists of an ElectroSpray Ionization source and an Orbitrap mass analyzer as well as with an Agilent Technologies Gas Chromatography (GC) coupled to a Leco Pegasus HT MS which consists of an Electron Impact ionization source and a Time of Flight mass analyzer (metaSysX GmbH, Germany). LC-MS measurements of the aqueous phase permitted the analyses of the secondary metabolites and GC-MS measurements allowed the analyses of the primary metabolites. After alignment and filtration of LC-MS data, annotation was accomplished by matching the extracted data from the chromatograms with library of reference compounds in terms of accurate mass and retention time. For GC-MS data processing and annotation, the Bioconductor package TargetSearch was used to transform retention time to retention index, to align the chromatograms, to extract the peaks, and to annotate them by comparing the spectra and the retention index to the Fiehn Library and to a user created library. The filtered data from all platforms was normalized first to the weight of samples used for extraction and according to sample 
median intensity group-wise and further combined to a final data matrix. PCA on normalized data was performed using the software $\mathrm{R}$ version 3.1.1. Differential metabolites were chosen according to statistically significant $(P$ value $<$ 0.05) based on $t$ tests using Metaboanalyst 4.0 (http:// www.metaboanalyst.ca/). Metabolic Pathways were constructed based on metaSysX's reference compound database by using VANTED [80].

\section{qRT-PCR}

The same RNA samples for the transcriptome analysis were reverse transcribed using a HiScript II 1st Strand cDNA Synthesis kit (Vazyme Biotech, Nanjing, China) with oligo (dT23) primer. qRT-PCR programs were performed on a LightCycler480 Real-Time PCR System using ChamQTM SYBR $^{\circ}$ qPCR Master Mix (Vazyme Biotech, Nanjing, China) according to the manufacturer's instructions. The sesame Histone H3.3 gene (SIN_1004293) was used as an internal control. The relative expression levels of 10 selected genes were detected with three biological replications and three technical replications using the $2^{-\Delta \Delta \mathrm{Ct}}$ method [81]. The gene-specific primers are listed in Additional file 1: Table S8.

\section{Additional files}

Additional file 1: Table S1. Summary of RNA-Seq data. Table S2. Significantly enriched KEGG pathways of the DEGs in ST and SS in response to salt stress $(P$-Value $<0.05)$. Table S3. List of genes that were exclusively up-regulated in ST genotype at all salt stress time points. Table S4. List of the core gene set involved in sesame response to salt stress. Table S5. GO terms enriched amongst the core salt-responsive genes in sesame (top 30 terms only). Table S6. The core metabolites involved in sesame response to salt stress. Table S7. The metabolites increased significantly and exclusively in ST genotype in response to salt stress. Table $\mathbf{S 8 .}$ Primers used in qRT-PCR analysis. (XLSX $90 \mathrm{~kb}$ )

Additional file 2: Figure S1. Pearson correlation analysis between samples. (PNG $790 \mathrm{~kb}$ )

Additional file 3: Figure S2. PCA clustering based on RNA-Seq data. (PNG $33 \mathrm{~kb}$ )

Additional file 4: Figure S3. Correlation analysis between $\mathrm{QRT}$-PCR and RNA-Seq data based on $\log _{2}$ fold change of 10 selected genes. (TIF $38 \mathrm{~kb}$ )

Additional file 5: Figure S4. GO enrichment of DEGs in ST and SS at different salt stress time points. (TIF $3120 \mathrm{~kb}$ )

Additional file 6: Figure S5. Expression patterns of the 101 active transcription factors in ST and SS under salt stress. (TIF $4811 \mathrm{~kb}$ )

Additional file 7: Figure S6. Metabolic pathways of the salt-responsive metabolites in sesame under salt stress. (TIF $3692 \mathrm{~kb}$ )

\section{Abbreviations}

ABA: Abscisic acid; AREB/ABFs: ABA-responsive element binding transcription factors; CIPKs: CBL-interacting protein kinases; FPKM: Fragments per kilobase of transcript per million fragments mapped; GABA: 4-Aminobutanoic acid; GC-MS: Gas chromatography mass spectrometer; LC-MS: Liquid chromatography mass spectrometer; LEA: Late embryogenesis abundant protein; NHXs: $\mathrm{Na}^{+} / \mathrm{H}^{+}$exchangers; PCA: Principal component analyses; PP2C: Probable protein phosphatase 2C; RFOs: Raffinose family oligosaccharides; ROS: Reactive oxygen species; SnRK2s: Subfamily 2 of the SNF1-related kinases; SOS: Salt overly sensitive; SS: Salt-sensitive; ST: Salttolerant

\section{Acknowledgments}

We sincerely thank Ms. Aili Liu and Ms. Mengyuan Wei for laboratory assistance and helpful discussions.

\section{Funding}

This work was supported by the Opening Project of the Key Laboratory of Biology and Genetic Improvement of Oil Crops, Ministry of Agriculture, P. R. China (KF2017007, KF2018003), the Natural Science Foundation of Shandong Province of China (ZR2018LC014), China Agriculture Research System (CARS14), the Agricultural Science and Technology Innovation Project of Chinese Academy of Agricultural Sciences (CAAS-ASTIP-2013-OCRI), Agricultural scientific and technological innovation project of Shandong Academy of Agricultural Sciences (CXGC2018E06), and the National Natural Science Foundation of China (31500223). The funders had no role in the experimental design, data collection and analysis or writing the manuscript.

\section{Availability of data and materials}

All data generated or analyzed during this study are available from the corresponding author on reasonable request.

\section{Authors' contributions}

YJZ, XRZ and JY conceived the study. DHL, RZ, XW, KD, LHW, YXZ, JYY and HHG performed the experiments and the data analysis. YJZ and JY performed the experiments and wrote the manuscript. XW, YJZ, KD and JY revised the manuscript. All authors have read and approved the final manuscript.

Ethics approval and consent to participate

Not applicable.

\section{Consent for publication}

Not applicable.

\section{Competing interests}

The authors declare that they have no competing interests.

\section{Publisher's Note}

Springer Nature remains neutral with regard to jurisdictional claims in published maps and institutional affiliations.

\section{Author details}

${ }^{1}$ Key Laboratory of Biology and Genetic Improvement of Oil Crops of the Ministry of Agriculture and Rural Affairs, Oil Crops Research Institute of the Chinese Academy of Agricultural Sciences, Wuhan 430062, China. ${ }^{2}$ Cotton Research Center, Shandong Academy of Agricultural Sciences, Jinan 250100, China. ${ }^{3}$ Centre d'Etude Régional pour l'Amélioration de I'Adaptation à la Sécheresse (CERAAS), Route de Khombole, 3320 Thiès, BP, Senegal.

Received: 18 October 2018 Accepted: 29 January 2019

Published online: 11 February 2019

\section{References}

1. Munns R, Gilliham M. Salinity tolerance of crops - what is the cost? New Phytol. 2015. https://doi.org/10.1111/nph.13519.

2. Rengasamy P. Soil processes affecting crop production in salt-affected soils. Funct Plant Biol. 2010. https://doi.org/10.1071/FP09249.

3. Zhu JK. Plant salt tolerance. Trends Plant Sci. 2001.

4. Flowers TJ. Improving crop salt tolerance. J Exp Bot. 2004. https:// doi.org/10.1093/jxb/erh003.

5. Roy SJ, Negrao S, Tester M. Salt resistant crop plants. Curr Opin Biotechnol. 2014. https://doi.org/10.1016/j.copbio.2013.12.004.

6. Ashraf M, Athar HR, Harris PJC, Kwon TR. Some prospective strategies for improving crop salt tolerance. Adv Agron. 2008. https://doi.org/10.1016/ S0065-2113(07)00002-8.

7. Munns R, Tester M. Mechanisms of salinity tolerance. Annu Rev Plant Biol. 2008:59:651-81.

8. Wang WS, Zhao XQ, Li M, Huang LY, Xu JL, Zhang F, Cui YR, Fu BY, Li ZK. Complex molecular mechanisms underlying seedling salt tolerance in rice revealed by comparative transcriptome and metabolomic profiling. J Exp Bot. 2016;67(1):405-19. 
9. Ben Saad R, Zouari N, Ben Ramdhan W, Azaza J, Meynard D, Guiderdoni E, Hassairi A. Improved drought and salt stress tolerance in transgenic tobacco overexpressing a novel A20/AN1 zinc-finger "AISAP" gene isolated from the halophyte grass Aeluropus littoralis. Plant Mol Biol. 2010. https://doi.org/10. 1007/s11103-009-9560-4.

10. Kumar S, Dhingra A, Daniell H. Plastid-expressed betaine aldehyde dehydrogenase gene in carrot cultured cells, roots, and leaves confers enhanced salt tolerance. Plant Physiol. 2004. https://doi.org/10.1104/pp.104.045187.

11. Jing P, Zou JZ, Kong L, Hu SQ, Wang BY, Yang J, Xie GS. OsCCD1, a novel small calcium-binding protein with one EF-hand motif, positively regulates osmotic and salt tolerance in rice. Plant Sci. 2016. https://doi.org/10.1016/j.plantsci.2016.03.011.

12. Yang Y, Tang RJ, Li B, Wang HH, Jin YL, Jiang CM, Bao Y, Su HY, Zhao N, Ma XJ, Yang L, Chen SL, Cheng XH, Zhang HX. Overexpression of a Populus trichocarpa $\mathrm{H}^{+}$-pyrophosphatase gene PtVP1.1 confers salt tolerance on transgenic poplar. Tree Physiol. 2015. https://doi.org/10.1093/treephys/tpv027.

13. Abebe T, Guenzi AC, Martin B, Cushman JC. Tolerance of mannitol-accumulating transgenic wheat to water stress and salinity. Plant Physiol. 2003;131(4):1748-55.

14. Qiao WH, Zhao XY, Li W, Luo Y, Zhang XS. Overexpression of AeNHX1, a root-specific vacuolar $\mathrm{Na}^{+} / \mathrm{H}^{+}$antiporter from Agropyron elongatum, confers salt tolerance to Arabidopsis and Festuca plants. Plant Cell Rep. 2007. https://doi.org/10.1007/s00299-007-0354-3.

15. Hmida-Sayari A, Gargouri-Bouzid R, Bidani A, Jaoua L, Savoure A, Jaoua S. Overexpression of $\Delta^{1}$-pyrroline-5-carboxylate synthetase increases proline production and confers salt tolerance in transgenic potato plants. Plant Sci. 2005. https://doi.org/10.1016/j.plantsci.2005.05.025.

16. Feki K, Quintero FJ, Khoudi H, Leidi EO, Masmoudi K, Pardo JM, Brini F. A constitutively active form of a durum wheat $\mathrm{Na}^{+} / \mathrm{H}^{+}$antiporter SOS1 confers high salt tolerance to transgenic Arabidopsis. Plant Cell Rep. 2014. https://doi.org/10.1007/s00299-013-1528-9.

17. Xiang Y, Tang N, Du H, Ye HY, Xiong LZ. Characterization of OsbZIP23 as a key player of the basic leucine zipper transcription factor family for conferring abscisic acid sensitivity and salinity and drought tolerance in Rice. Plant Physiol. 2008;148(4):1938-52.

18. Munns R, James RA, Xu B, Athman A, Conn SJ, Jordans C, Byrt CS, Hare RA, Tyerman SD, Tester M, Plett D, Gilliham M. Wheat grain yield on saline soils is improved by an ancestral $\mathrm{Na}^{+}$transporter gene. Nat Biotechnol. 2012. https://doi.org/10.1038/nbt.2120.

19. Namiki M. Nutraceutical functions of sesame: a review. Crit Rev Food Sci. 2007. https://doi.org/10.1080/10408390600919114.

20. Shahidi F, Liyana-Pathirana CM, Wall DS. Antioxidant activity of white and black sesame seeds and their hull fractions. Food Chem. 2006. https://doi.org/10.1016/j.foodchem.2005.08.009.

21. Ramirez R, Gutierrez A, Villafane R, Lizaso Jl. Salt tolerance of sesame genotypes at germination, vegetative, and maturity stages. Commun Soil Sci Plan. 2005. https://doi.org/10.1080/00103620500253324

22. Li DH, Dossa K, Zhang YX, Wei X, Wang LH, Zhang YJ, Liu AL, Zhou R, Zhang XR. GWAS uncovers differential genetic bases for drought and salt tolerances in sesame at the germination stage. Genes-Basel. 2018. https://doi.org/10.3390/Genes9020087.

23. Bazrafshan AH, Ehsanzadeh P. Growth, photosynthesis and ion balance of sesame (Sesamum indicum L.) genotypes in response to $\mathrm{NaCl}$ concentration in hydroponic solutions. Photosynthetica. 2014;52(1):134-47.

24. Koca H, Bor M, Ozdemir F, Turkan I. The effect of salt stress on lipid peroxidation, antioxidative enzymes and proline content of sesame cultivars. Environ Exp Bot. 2007. https://doi.org/10.1016/j.envexpbot.2006.12.005.

25. ElSayed Al, Rafudeen MS, Golldack D. Physiological aspects of raffinose family oligosaccharides in plants: protection against abiotic stress. Plant Biol. 2014. https://doi.org/10.1111/plb.12053.

26. Liu A, Xiao Z, Li MW, Wong FL, Yung WS, Ku YS, Wang Q, Wang X, Xie M, Yim AK, Chan TF, Lam HM. Transcriptomic reprogramming in soybean seedlings under salt stress. Plant Cell Environ. 2018. https://doi.org/10.1111/pce.13186.

27. Turkan I, Demiral T. Recent developments in understanding salinity tolerance. Environ Exp Bot. 2009;67(1):2-9.

28. Bohnert HJ, Nelson DE, Jensen RG. Adaptations to environmental stresses. Plant Cell. 1995;7(7):1099.

29. Hare PD, Cress WA, Van Staden J. Dissecting the roles of osmolyte accumulation during stress. Plant Cell Environ. 1998;21(6):535-53.

30. Chen $\mathrm{THH}$, Murata N. Enhancement of tolerance of abiotic stress by metabolic engineering of betaines and other compatible solutes. Curr Opin Plant Biol. 2002;5(3):250-7.
31. Garg AK, Kim JK, Owens TG, Ranwala AP, Do Choi Y, Kochian LV, Wu RJ. Trehalose accumulation in rice plants confers high tolerance levels to different abiotic stresses. Proc Natl Acad Sci U S A. 2002;99(25):15898-903.

32. Hausler RE, Ludewig F, Krueger S. Amino acids - a life between metabolism and signaling. Plant Sci. 2014. https://doi.org/10.1016/j.plantsci.2014.09.011.

33. Maeda $H$, Dudareva N. The shikimate pathway and aromatic amino acid biosynthesis in plants. Annu Rev Plant Biol. 2012. https://doi. org/10.1146/annurev-arplant-042811-105439.

34. Stepansky A, Galili G. Synthesis of the Arabidopsis bifunctional lysineketoglutarate reductase/saccharopine dehydrogenase enzyme of lysine catabolism is concertedly regulated by metabolic and stress-associated signals. Plant Physiol. 2003. https://doi.org/10.1104/pp.103.026294.

35. Facchini PJ, Hagel J, Zulak KG. Hydroxycinnamic acid amide metabolism: physiology and biochemistry. Can J Bot. 2002. https://doi.org/10.1139/B02-065.

36. Forde BG, Lea PJ. Glutamate in plants: metabolism, regulation, and signalling. J Exp Bot. 2007. https://doi.org/10.1093/jxb/erm121.

37. Petrov V, Hille J, Mueller-Roeber B, Gechev TS. ROS-mediated abiotic stress-induced programmed cell death in plants. Front Plant Sci. 2015. https://doi.org/10.3389/Fpls.2015.00069.

38. Steinhorst L, Kudla J. Calcium and reactive oxygen species rule the waves of signaling. Plant Physiol. 2013. https://doi.org/10.1104/pp.113.222950.

39. Chung JS, Zhu JK, Bressan RA, Hasegawa PM, Shi HH. Reactive oxygen species mediate $\mathrm{Na}^{+}$-induced SOS1 mRNA stability in Arabidopsis. Plant J. 2008. https://doi.org/10.1111/j.1365-313X.2007.03364.X.

40. Verslues PE, Batelli G, Grillo S, Agius F, Mm YS, Zhu J, Agarwal M, Katiyar-Agarwal S, Zhu JK. Interaction of SOS2 with nucleoside diphosphate kinase 2 and catalases reveals a point of connection between salt stress and $\mathrm{H}_{2} \mathrm{O}_{2}$ signaling in Arabidopsis thaliana. Mol Cell Biol. 2007. https://doi.org/10.1128/Mcb.00429-07.

41. Ahmad R, Kim MD, Back KH, Kim HS, Lee HS, Kwon SY, Murata N, Chung WI, Kwak SS. Stress-induced expression of choline oxidase in potato plant chloroplasts confers enhanced tolerance to oxidative, salt, and drought stresses. Plant Cell Rep. 2008. https://doi.org/10.1007/s00299-007-0479-4.

42. Miller G, Suzuki N, Ciftci-Yilmaz S, Mittler R. Reactive oxygen species homeostasis and signalling during drought and salinity stresses. Plant Cell Environ. 2010. https://doi.org/10.1111/j.1365-3040.2009.02041.x.

43. Zheng LY, Meng Y, Ma J, Zhao XL, Cheng TL, Ji J, Chang EM, Meng C, Deng $\mathrm{N}$, Chen LZ, Shi SQ, Jiang ZP. Transcriptomic analysis reveals importance of ROS and phytohormones in response to short-term salinity stress in Populus tomentosa. Front Plant Sci. 2015. https://doi.org/10.3389/Fpls.2015.00678.

44. Eltayeb AE, Kawano N, Badawi GH, Kaminaka H, Sanekata T, Shibahara T, Inanaga S, Tanaka K. Overexpression of monodehydroascorbate reductase in transgenic tobacco confers enhanced tolerance to ozone, salt and polyethylene glycol stresses. Planta. 2007. https://doi.org/10.1007/s00425-006-0417-7.

45. Zhu JK. Regulation of ion homeostasis under salt stress. Curr Opin Plant Biol. 2003. https://doi.org/10.1016/S1369-5266(03)00085-2.

46. Qiu QS, Guo Y, Quintero FJ, Pardo JM, Schumaker KS, Zhu JK. Regulation of vacuolar $\mathrm{Na}^{+} / \mathrm{H}^{+}$exchange in Arabidopsis thaliana by the salt-overly-sensitive (SOS) pathway. J Biol Chem. 2004. https://doi.org/10.1074/jbc.M307982200.

47. Zhu JK. Abiotic stress signaling and responses in plants. Cell. 2016;167(2):313-24.

48. Tang RJ, Liu H, Bao Y, Lv QD, Yang L, Zhang HX. The woody plant poplar has a functionally conserved salt overly sensitive pathway in response to salinity stress. Plant Mol Biol. 2010. https://doi.org/10.1007/s11103-010-9680-x.

49. Olias R, Eljakaoui Z, Li J, De Morales PA, Marin-Manzano MC, Pardo JM, Belver A. The plasma membrane $\mathrm{Na}^{+} / \mathrm{H}^{+}$antiporter SOS1 is essential for salt tolerance in tomato and affects the partitioning of $\mathrm{Na}+$ between plant organs. Plant Cell Environ. 2009. https://doi.org/10.1111/j.1365-3040.2009.01971.x.

50. Sathee L, Sairam RK, Chinnusamy V, Jha SK. Differential transcript abundance of salt overly sensitive (SOS) pathway genes is a determinant of salinity stress tolerance of wheat. Acta Physiol Plant. 2015. https:/doi.org/10.1007/S11738-015-1910-Z.

51. Zhu JK. Salt and drought stress signal transduction in plants. Annu Rev Plant Biol. 2002. https://doi.org/10.1146/annurev.arplant.53.091401.143329.

52. Qiu QS, Guo Y, Dietrich MA, Schumaker KS, Zhu JK. Regulation of SOS1, a plasma membrane $\mathrm{Na}^{+} / \mathrm{H}^{+}$exchanger in Arabidopsis thaliana, by SOS2 and SOS3. Proc Natl Acad Sci U S A. 2002. https://doi.org/10.1073/pnas.122224699.

53. Qi Z, Spalding EP. Protection of plasma membrane $K^{+}$transport by the salt overly sensitive1 $\mathrm{Na}^{+}-\mathrm{H}^{+}$antiporter during salinity stress. Plant Physiol. 2004;136(1):2548-55.

54. Selvakumar G, Shagol CC, Kim K, Han S, Sa T. Spore associated bacteria regulates maize root $\mathrm{K}+/ \mathrm{Na}+$ ion homeostasis to promote salinity tolerance during arbuscular mycorrhizal symbiosis. BMC Plant Biol. 2018. https://doi.org/10.1186/\$12870-018-1317-2. 
55. Ng LM, Melcher K, Teh BT, Xu HE. Abscisic acid perception and signaling: structural mechanisms and applications. Acta Pharmacol Sin. 2014;35(5):567.

56. Lee KH, Piao HL, Kim HY, Choi SM, Jiang F, Hartung W, Hwang I, Kwak JM, Lee IJ, Hwang I. Activation of glucosidase via stress-induced polymerization rapidly increases active pools of abscisic acid. Cell. 2006;126(6):1109-20.

57. Ma Y. Regulators of PP2C phosphatase activity function as abscisic acid sensors. Science. 2009;324(5930):1064-8.

58. Park SY, Fung P, Nishimura N, Jensen DR, Fujii H, Zhao Y, Lumba S, Santiago J, Rodrigues A, Chow TFF, Alfred SE, Bonetta D, Finkelstein R, Provart NJ, Desveaux D, Rodriguez PL, McCourt P, Zhu JK, Schroeder Jl, Volkman BF, Cutler SR. Abscisic acid inhibits type 2C protein phosphatases via the PYR/ PYL family of START proteins. Science. 2009;324(5930):1068-71.

59. Fujita Y, Nakashima K, Yoshida T, Katagiri T, Kidokoro S, Kanamori N, Umezawa T, Fujita M, Maruyama K, Ishiyama K, Kobayashi M, Nakasone S, Yamada K, Ito T, Shinozaki K, Yamaguchi-Shinozaki K. Three SnRK2 protein kinases are the Main positive regulators of abscisic acid signaling in response to water stress in Arabidopsis. Plant Cell Physiol. 2009;50(12):2123-32.

60. Yoshida T, Fujita Y, Sayama H, Kidokoro S, Maruyama K, Mizoi J, Shinozaki K, Yamaguchi-Shinozaki K. AREB1, AREB2, and ABF3 are master transcription factors that cooperatively regulate ABRE-dependent ABA signaling involved in drought stress tolerance and require ABA for full activation. Plant J. 2010. https://doi.org/10.1111/j.1365-313X.2009.04092.x.

61. Hobo T, Kowyama Y, Hattori T. A bZIP factor, TRAB1, interacts with VP1 and mediates abscisic acid-induced transcription. Proc Natl Acad Sci U S A. 1999. https://doi.org/10.1073/pnas.96.26.15348.

62. Qu GZ, Zang LN, Hu XL, Gao CQ, Zheng TC, Li KL. Co-transfer of LEA and bZip genes from Tamarix confers additive salt and osmotic stress tolerance in transgenic tobacco. Plant Mol Biol Rep. 2012. https://doi.org/10.1007/s11105-011-0371-9.

63. Shi SQ, Shi Z, Jiang ZP, Qi LW, Sun XM, Li CX, Liu JF, Xiao WF, Zhang SG. Effects of exogenous GABA on gene expression of Caragana intermedia roots under $\mathrm{NaCl}$ stress: regulatory roles for $\mathrm{H}_{2} \mathrm{O}_{2}$ and ethylene production. Plant Cell Environ. 2010;33(2):149-62.

64. Bais HP, Ravishankar GA. Role of polyamines in the ontogeny of plants and their biotechnological applications. Plant Cell Tiss Org. 2002;69(1):1-34.

65. Sanchez DH, Cuevas JC, Chiesa MA, Ruiz OA. Free spermidine and spermine content in Lotus glaber under long-term salt stress. Plant Sci. 2005. https://doi.org/10.1016/j.plantsci.2004.09.025.

66. Liu C, Zhao L, Yu G. The dominant glutamic acid metabolic flux to produce gamma-amino butyric acid over proline in Nicotiana tabacum leaves under water stress relates to its significant role in antioxidant activity. J Integr Plant Biol. 2011. https://doi.org/10.1111/j.1744-7909.2011.01049.x.

67. Krishnamurthy $R$, Bhagwat KA. Polyamines as modulators of salt tolerance in rice cultivars. Plant Physiol. 1989;91(2):500-4.

68. Nahar K, Hasanuzzaman M, Rahman A, Alam MM, Mahmud JA, Suzuki T, Fujita M. Polyamines confer salt tolerance in mung bean (Vigna radiata L.) by reducing sodium uptake, improving nutrient homeostasis, antioxidant defense, and methylglyoxal detoxification systems. Front Plant Sci. 2016. https://doi.org/10.3389/fpls.2016.01104.

69. Roychoudhury A, Basu S, Sengupta DN. Amelioration of salinity stress by exogenously applied spermidine or spermine in three varieties of indica rice differing in their level of salt tolerance. J Plant Physiol. 2011. https://doi.org/10.1016/j.jplph.2010.07.009.

70. Klein A, Keyster M, Ludidi N. Caffeic acid-induced salt stress tolerance is mediated by nitric oxide and hydrogen peroxide scavenging enzymes in soybean root nodules. S Afr J Bot. 2013. https://doi.org/10.1016/j.sajb.2013.02.099.

71. Wan YY, Zhang Y, Zhang L, Zhou ZQ, Li X, Shi QH, Wang XJ, Bai JG. Caffeic acid protects cucumber against chilling stress by regulating antioxidant enzyme activity and proline and soluble sugar contents. Acta Physiol Plant. 2015. https://doi.org/10.1007/S11738-014-1706-6.

72. Hu W, Huang C, Deng X, Zhou S, Chen L, Li Y, Wang C, Ma Z, Yuan Q, Wang Y, Cai R, Liang X, Yang G, He G. TaASR1, a transcription factor gene in wheat, confers drought stress tolerance in transgenic tobacco. Plant Cell Environ. 2013. https://doi.org/10.1111/pce.12074.

73. Lei YT, Xu YX, Hettenhausen C, Lu CK, Shen GJ, Zhang CP, Li J, Song J, Lin $\mathrm{HH}, \mathrm{Wu} J \mathrm{Q}$. Comparative analysis of alfalfa (Medicago sativa L.) leaf transcriptomes reveals genotype-specific salt tolerance mechanisms. BMC Plant Biol. 2018, https://doi.org/10.1186/s12870-018-1250-4.

74. Kim D, Landmead B, Salzberg SL. HISAT: a fast spliced aligner with low memory requirements. Nat Methods. 2015. https://doi.org/10.1038/Nmeth.3317.
75. Dossa K, Li DH, Wang LH, Zheng XM, Liu AL, Yu JY, Wei X, Zhou R, Fonceka D, Diouf D, Liao BS, Ciss N, Zhang XR. Transcriptomic, biochemical and physio-anatomical investigations shed more light on responses to drought stress in two contrasting sesame genotypes. Sci Rep-Uk. 2017. https://doi.org/10.1038/S41598-017-09397-6.

76. Anders S, Huber W. Differential expression analysis for sequence count data. Genome Biol. 2010. https://doi.org/10.1186/Gb-2010-11-10-R106.

77. Young MD, Wakefield MJ, Smyth GK, Oshlack A. Gene ontology analysis for RNA-seq: accounting for selection bias. Genome Biol. 2010. https://doi.org/10.1186/Gb-2010-11-2-R14.

78. Eisen MB, Spellman PT, Brown PO, Botstein D. Cluster analysis and display of genome-wide expression patterns. Proc Natl Acad Sci U S A. 1998;95(25):14863-8.

79. Giavalisco P, Kohl K, Hummel J, Seiwert B, Willmitzer L. C-13 isotope-labeled metabolomes allowing for improved compound annotation and relative quantification in liquid chromatography-mass spectrometry-based Metabolomic research. Anal Chem. 2009. https://doi.org/10.1021/ac900979e.

80. Junker BH, Klukas C, Schreiber F. VANTED: A system for advanced data analysis and visualization in the context of biological networks. Bmc Bioinformatics. 2006. https://doi.org/10.1186/1471-2105-7-109.

81. Livak KJ, Schmittgen TD. Analysis of relative gene expression data using real-time quantitative PCR and the $2^{-\Delta \Delta C t}$ method. Methods. 2001. https://doi.org/10.1006/meth.2001.1262.

\section{Ready to submit your research? Choose BMC and benefit from:}

- fast, convenient online submission

- thorough peer review by experienced researchers in your field

- rapid publication on acceptance

- support for research data, including large and complex data types

- gold Open Access which fosters wider collaboration and increased citations

- maximum visibility for your research: over $100 \mathrm{M}$ website views per year

At BMC, research is always in progress.

Learn more biomedcentral.com/submissions 